\title{
The Effect of Continuous Subcutaneous Insulin Infusion and Conventional Insulin Regimes on 24-Hour Variations of Blood Glucose and Intermediary Metabolites in the Third Trimester of Diabetic Pregnancy
}

\author{
J. M. Potter, J. P. D. Reckless and D. R. Cullen \\ Royal Hallamshire Hospital, Sheffield, UK
}

Summary. Twenty-four hour metabolic profiles were performed in the third trimester of pregnancy in seven diabetic women; first when optimally controlled using conventional insulin regimes and subsequently when controlled with continuous subcutaneous insulin infusion. Seven non-diabetic women were also studied. Mean \pm SD $24 \mathrm{~h}$ metabolite levels in the diabetics before and during continuous subcutaneous insulin infusion and in the controls were respectively: glucose $-5.8 \pm 1.2 ; 5.0 \pm 0.9 ; 4.7 \pm 0.8 \mathrm{mmol} / 1$; total ketone bodies $-0.2 \pm 0.06 ; 0.15 \pm 0.05 ; 0.11 \pm$ $0.04 \mathrm{mmol} / 1$; lactate $-0.90 \pm 0.33 ; 0.90 \pm 0.24 ; 1.05$ $\pm 0.18 \mathrm{mmol} / \mathrm{l}$; alanine $-0.29 \pm 0.06 ; 0.30 \pm 0.06$; $0.31 \pm 0.03 \mathrm{mmol} / 1$. Total ketone body levels were significantly elevated $(p<0.05)$ on conventional therapy but not on continuous subcutaneous insulin infusion compared with controls. Variations in metabolites over $24 \mathrm{~h}$, as measured by mean standard deviations, were increased for glucose $(p<0.001)$ and for total ketone bodies $(p<0.05)$ on the conventional regimes we employed compared with controls. On continuous subcutaneous insulin infusion variations of blood glucose were not affected whereas variations in total ketone bodies were no different from controls. The best possible maternal metabolic control is necessary for normal foetal development and continuous subcutaneous insulin infusion provides a method of achieving this.

Key words: Diabetes in pregnancy, infusions - parenteral, insulin, blood glucose, metabolism - lipolysis, metabolism - glycolysis, continuous subcutaneous insulin infusion, insulin therapy, insulin dependent diabetes.
Diabetic pregnancy is associated with increased rates of perinatal mortality and morbidity [1-3]. By strict attention to diabetic control in association with close obstetric and paediatric supervision, it is possible to reduce appreciably the incidence of perinatal mortality [4-6]. It is likely that strict control of blood glucose $[7,8]$ as well as of other major intermediary metabolites [9], is an important factor in these improved results.

Continuous subcutaneous insulin infusion (CSII) has been suggested as a means of achieving a more physiological supply of insulin $[10,11]$. The requirement for optimal diabetic control during pregnancy offers an opportunity to compare the effects of CSII and conventional insulin regimes.

We have, therefore, performed $24 \mathrm{~h}$ metabolic profiles in seven insulin-requiring diabetic women whose blood glucose was optimally controlled on their conventional insulin regime and subsequently on CSII. The results have been compared with metabolic profiles obtained from seven normal women of the same gestational age.

\section{Patients and Methods}

\section{Patients}

Seven insulin-requiring diabetic women and seven women with normal carbohydrate metabolism matched for age, weight, percentage of desirable body weight and parity were studied (Table 1). The severity of the diabetes as assessed by the White classification [12] is shown in Table 1. The insulin-requiring diabetics included two women with gestational diabetes (patients 1 and 4, Table 2). Patient 1 had mild hypertension during pregnancy and was taking methyl dopa $250 \mathrm{mg}$ three times a day. The other patients did not suffer from any disease other than diabetes and were not on any medication other than routine iron and vitamin supplements. All women were on twice daily injections of short and medium-acting insulin 
Table 1. Details of control subjects and patients studied

\begin{tabular}{|c|c|c|c|c|c|c|c|c|c|}
\hline & \multirow[t]{2}{*}{$\begin{array}{l}\text { Mean age } \\
\text { (years) }\end{array}$} & \multirow[t]{2}{*}{$\begin{array}{l}\text { Mean weight } \\
(\mathrm{kg})\end{array}$} & \multirow[t]{2}{*}{$\begin{array}{l}\text { Mean desirable } \\
\text { body weight }(\%)\end{array}$} & \multirow{2}{*}{$\begin{array}{l}\text { Gestational } \\
\text { age at study } \\
\text { (weeks) }\end{array}$} & \multirow{2}{*}{$\begin{array}{l}\text { Parity } \\
\text { (infants/ } \\
\text { group) }\end{array}$} & \multicolumn{4}{|c|}{$\begin{array}{l}\text { Severity of diabetes } \\
\text { White class (12) }\end{array}$} \\
\hline & & & & & & $\mathrm{B}$ & $\mathrm{C}$ & $\mathrm{D}$ & $\mathrm{F}$ \\
\hline Control subjects $(n=7)$ & $28 \pm 2$ & $62 \pm 9$ & $108 \pm 19$ & 33 & 4 & - & - & - & - \\
\hline Diabetics $(n=7)$ & $27 \pm 5$ & $58 \pm 7$ & $101 \pm 15$ & $33 / 36$ & 4 & 5 & 1 & - & 1 \\
\hline
\end{tabular}

a Non-pregnant weight

b Calculated using weights before pregnancy from the table of the Metropolitan Life Insurance Society [31]

Table 2. Details of diet and insulin therapy during $24 \mathrm{~h}$ profiles before and during continuous subcutaneous insulin infusion

\begin{tabular}{|c|c|c|c|c|c|c|c|c|c|c|}
\hline \multirow[t]{2}{*}{ Patient } & \multicolumn{4}{|c|}{ Conventional regime } & \multicolumn{6}{|c|}{ Continuous subcutaneous insulin infusion } \\
\hline & $\begin{array}{l}\text { Dietary } \\
\text { carbohy- } \\
\text { drate } \\
(\mathrm{g} / 24 \mathrm{~h})\end{array}$ & $\begin{array}{l}07.30 \mathrm{~h} \\
\text { (units of inst }\end{array}$ & $17.30 \mathrm{~h}$ & $\begin{array}{l}\text { Total } \\
\text { dose } \\
\text { (units } / 24 \text { h) }\end{array}$ & Basal & $\begin{array}{l}\text { Breakfast } \\
\text { (units of in }\end{array}$ & Lunch & Supper & 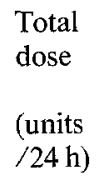 & $\begin{array}{l}\% \text { of } \\
\text { convention- } \\
\text { al regime }\end{array}$ \\
\hline $1^{a}$ & 150 & $\mathrm{~A} 30 / \mathrm{S} 24$ & A $24 / \mathrm{S} 22$ & 100 & $4.0 / 1.3^{\mathrm{b}}$ & 13 & 13 & 13 & 96 & 96 \\
\hline 2 & 200 & A $42 / \mathrm{M} 28$ & A $16 / \mathrm{M} 24$ & 110 & 1.3 & 47 & 20 & 20 & 115 & 105 \\
\hline 3 & 160 & $\mathrm{~A} 48 / \mathrm{S} 20$ & A $16 / \mathrm{S} 20$ & 104 & 1.0 & 55 & 15 & 15 & 106 & 102 \\
\hline $4^{a}$ & 160 & A 34 A 8 & A 32 A 6 & 80 & 0.7 & 30 & 17 & 17 & 78 & 98 \\
\hline 5 & 150 & So $16 / \mathrm{I} 18$ & I 14 & 48 & 0.7 & 16 & 8 & 8 & 46 & 96 \\
\hline 6 & 170 & A 40 & A $20 / \mathrm{M} 30$ & 90 & $0.7 / 1.0^{\mathrm{b}}$ & 40 & 20 & 20 & 97 & 108 \\
\hline 7 & 180 & $\mathrm{~A} 30 / \mathrm{S} 22$ & A $18 /$ S 8 & 78 & 0.7 & 23 & 15 & 15 & 67 & 86 \\
\hline
\end{tabular}

A - Actrapid; S - Semitard; M - Monotard; So - Soluble; I - Isophane

a Gestational diabetic - extra insulin injections in patient 4 given at $11.30 \mathrm{~h}$ and $22.00 \mathrm{~h}$

${ }^{b}$ Dual basal rate used. First figure - daytime; second figure - night-time; rates changed at $21.00 \mathrm{~h}$

combinations (Table 2) except patient 4 , in whom four daily injections of Actrapid insulin proved more effective than twice daily insulin mixtures.

The seven normal pregnant women had a normal $50 \mathrm{~g}$ oral glucose tolerance test [13] and did not suffer from any other disease. Three women had a suspected placenta praevia without bleeding and one had mild hypertension which resolved on bed rest. The pregnancies were otherwise normal.

\section{Protocol}

The diabetic women were admitted at 32 weeks gestation for in-patient control. On admission blood glucose levels were measured routinely at least four times daily at $06.00,11.00,15.00$ and $21.00 \mathrm{~h}$ using an Ames Eyetone Reflectance Meter and the results were periodically checked with laboratory analyses on the same specimens. Patients were seen daily and appropriate adjustments made in insulin dosage. A period of 2 weeks was allowed to achieve optimum diabetic control on the conventional insulin regime before performing a $24 \mathrm{~h}$ metabolic profile.

An indwelling cannula was sited in one arm at $07.30 \mathrm{~h}$ and was kept patent using $0.13 \mathrm{~mol} / 1$ sodium citrate solution diluted 1 in 5 with $0.154 \mathrm{mmol} / 1$ saline. The samples were taken hourly from 08.00 to $24.00 \mathrm{~h}$ and at $02.00,04.00,06.00$ and $07.00 \mathrm{~h}$. Meals were taken at $08.00,12.00$ and $18.00 \mathrm{~h}$ and injections of insulin were given at 07.30 and $17.30 \mathrm{~h}$. Patients remained ambulant during the study but rested for $5 \mathrm{~min}$ before sampling.

The patients were then commenced on CSII using a Pye Dynamic MS16 syringe driver (weight $227 \mathrm{~g}$; size $16.5 \mathrm{~cm} \times 8.0 \mathrm{~cm} \times$ $2.8 \mathrm{~cm}$ ) which was battery driven and carried by the patient in a shoulder holster and connected to a plastic cannula (Lectrocath $100 \mathrm{~cm}$; bore $1 \mathrm{~mm}$ internal, $2 \mathrm{~mm}$ external) with a butterfly tip inserted SC in the upper arm. The cannula was held in place with tape, and the implantation site was protected by gauze and a Netalast bandage.

A basal infusion of insulin was administered throughout the $24 \mathrm{~h}$ which was supplemented by an augmented rate for $1 \mathrm{~h}$ over meals starting $30 \mathrm{~min}$ before meals. The basal infusion for each patient was arbitrarily fixed at $0.66 \mathrm{units} / \mathrm{h}$. The augmented rate was calculated by subtracting the total basal insulin dosage from the total daily insulin dosage on conventional therapy. This was then $\mathrm{di}$ vided so that half the dosage was given over breakfast and a quarter over each of the other two main meals. In some patients the basal and augmented infusion rates had to be further adjusted to achieve fasting and $3 \mathrm{~h}$ post-prandial blood glucose levels of between 3.0 and $6.0 \mathrm{mmol} / \mathrm{l}$ (Table 2), Rates of infusion between 0.33 and 263 units/ $h$ could be readily obtained without diluting the insulin using standard insulin preparations and disposable syringes. In each patient, short-acting insulin of the same purity as that used for conventional regimes was used (Table 2). During insulin infusion, patients were freely ambulant and were able to bath, sleep and eat without hindrance. When control was re-established using this method of insulin administration, a second metabolic profile was performed, approximately 2 weeks after the first profile. Patients were then maintained up to and including delivery using CSII. Dietary carbohydrate intake for each patient (Table 2) was the same during both conventional insulin therapy and CSII.

Women with normal carbohydrate metabolism were admitted overnight before the study and ate a normal diet. A $24 \mathrm{~h}$ metabolic profile was performed in the same way as in the diabetic patients and a $50 \mathrm{~g}$ oral glucose tolerance test was performed in each of the 
Table 3. $24 \mathrm{~h}$ levels and mean of standard deviations of blood glucose, total body ketones, lactate and alanine in the third trimester of pregnancy in seven normal and seven diabetic woman treated with either conventional regimes or continuous subcutaneous insulin infusion (CSII)

\begin{tabular}{|c|c|c|c|c|c|c|c|c|c|c|c|c|}
\hline & \multirow[t]{2}{*}{$\begin{array}{l}\text { Control } \\
\text { subjects }\end{array}$} & \multirow[t]{2}{*}{$\begin{array}{l}\text { Conven- } \\
\text { tional } \\
\text { regime }\end{array}$} & \multirow[t]{2}{*}{ CSII } & \multicolumn{3}{|c|}{$\begin{array}{l}\text { Significance } \\
\text { of group } \\
\text { differences }\end{array}$} & \multirow[t]{2}{*}{$\begin{array}{l}\text { Control } \\
\text { subjects }\end{array}$} & \multirow[t]{2}{*}{$\begin{array}{l}\text { Conven- } \\
\text { tional } \\
\text { regime }\end{array}$} & \multirow[t]{2}{*}{ CSII } & \multicolumn{3}{|c|}{$\begin{array}{l}\text { Significance } \\
\text { of group } \\
\text { differences }\end{array}$} \\
\hline & & & & A & B & $\mathrm{C}$ & & & & A & $B$ & $\mathrm{C}$ \\
\hline $\begin{array}{l}\text { Glucose } \\
(\mathrm{mmol} / \mathrm{l})\end{array}$ & $4.7 \pm 0.8$ & $5.8 \pm 1.2$ & $5.0 \pm 0.9$ & - & - & - & $0.8 \pm 0.1$ & $2.0 \pm 0.8$ & $1.7 \pm 0.3$ & c & - & c \\
\hline $\begin{array}{l}\text { Total } \\
\text { ketone bodies } \\
(\mathrm{mmol} / 1)\end{array}$ & $0.11 \pm 0.04$ & $0.20 \pm 0.06$ & $0.15 \pm 0.05$ & a & b & - & $0.030 \pm 0.009$ & $0.082 \pm 0.058$ & $0.057 \pm 0.034$ & a & $\mathrm{b}$ & - \\
\hline $\begin{array}{l}\text { Lactate } \\
(\mathrm{mmol} / 1\end{array}$ & $1.05 \pm 0.18$ & $0.90 \pm 0.33$ & $0.90 \pm 0.24$ & - & - & - & $0.33 \pm 0.11$ & $0.25 \pm 0.13$ & $0.22 \pm 0.24$ & - & - & - \\
\hline $\begin{array}{l}\text { Alanine } \\
(\mathrm{mmol} / \mathrm{l})\end{array}$ & $0.31 \pm 0.03$ & $0.29 \pm 0.06$ & $0.30 \pm 0.06$ & - & - & - & $0.047 \pm 0.011$ & $0.046 \pm 0.022$ & $0.055 \pm 0.024$ & - & - & - \\
\hline
\end{tabular}

$\mathrm{A}$ - control versus conventional regime; $\mathrm{B}$ - conventional regime versus CSII; $\mathrm{C}$ - control versus CSII

Results expressed as mean \pm SD

Significance of group differences: ${ }^{\mathrm{a}} p<0.05,{ }^{\mathrm{b}} p<0.01,{ }^{\mathrm{c}} p<0.001$

women within 1 week of the metabolic profile. All women gave informed consent to measurement of the metabolic profiles and the diabetic women to the use of CSII.

\section{Metabolic Estimations}

Two $\mathrm{ml}$ blood was taken from the patients at each sample point and added to cooled tubes containing $5 \mathrm{ml}$ of $5 \% \mathrm{~W} / \mathrm{v}$ perchloric acid. Precise amounts of blood and perchloric acid were determined gravimetrically. The tubes were then centrifuged twice and within 10 min the supernatant was separated and stored at $-20^{\circ} \mathrm{C}$. Blood glucose [14], lactate [15], alanine [16], 3-hydroxybutyrate [17] and acetoacetate [18] levels were estimated using spectrophotometric techniques. Blood acetoacetate levels were measured within $24 \mathrm{~h}$ and other assays within 2 weeks. The sum of acetoacetate and 3-hydroxybutyrate levels are referred to as total ketone bodies.

Statistical comparisons between groups were made using Student's $t$ test (Welch approximation) [19]. Analyses of the differences in mean standard deviations between groups was carried out using the same method after a $\log$ transformation of the data.

\section{Results}

\section{Insulin Requirements}

The amounts of insulin administered to the diabetic women during the metabolic profiles are shown in Table 2. Patients received similar amounts of insulin on CSII compared with conventional therapy. Infusion rates varied from 0.7 to 1.3 units insulin/ $h$ in the basal overnight state. Small changes within this narrow infusion range caused noticeable differences in fasting glucose levels. In two patients it was necessary to have different basal rates during the daytime and at night (patients 1 and 6). The insulin administered over meals on CSII ranged from 8 to 55 units within the group and there were marked differences in insulin requirements in the same patient with different meals. Breakfast tended to require the most insulin in all patients, and in one, more than a threefold increase was needed (patient 3). It was found practicable to maintain CSII in patients for periods varying from 3 weeks to 3 months.

\section{Blood Metabolites}

The mean $24 \mathrm{~h}$ glucose values were not significantly different between the groups (Table 3 ). The variability in blood glucose values as assessed by the mean standard deviation throughout the $24 \mathrm{~h}$ period was greater in the diabetic patients treated with conventional insulin regimes compared with controls $(p<$ 0.001 ) but this was not improved by CSII. The variations in blood glucose over $24 \mathrm{~h}$ in the diabetics are shown in Figure 1. The levels of blood glucose in diabetics on conventional regimes were elevated at most time points compared with values in the controls, the differences being significant at $09.00,10.00$ and $23.00 \mathrm{~h}(p<0.02, p<0.05$ and $p<0.02$ respectively). On CSII the levels of blood glucose were closer to those in non-diabetics but were reduced below normal at $12.00 \mathrm{~h}(p<0.05)$ although symptomatic hypoglycaemia did not occur. Within the diabetic group the use of CSII was associated with better glucose control over breakfast, the difference at $09.00 \mathrm{~h}$ being significant $(p<0.01)$. In the early hours of the morning, blood glucose levels in both diabetic groups were similar and tended to remain above normal.

Mean $24 \mathrm{~h}$ total ketone body levels were significantly elevated in the diabetics treated with conven- 

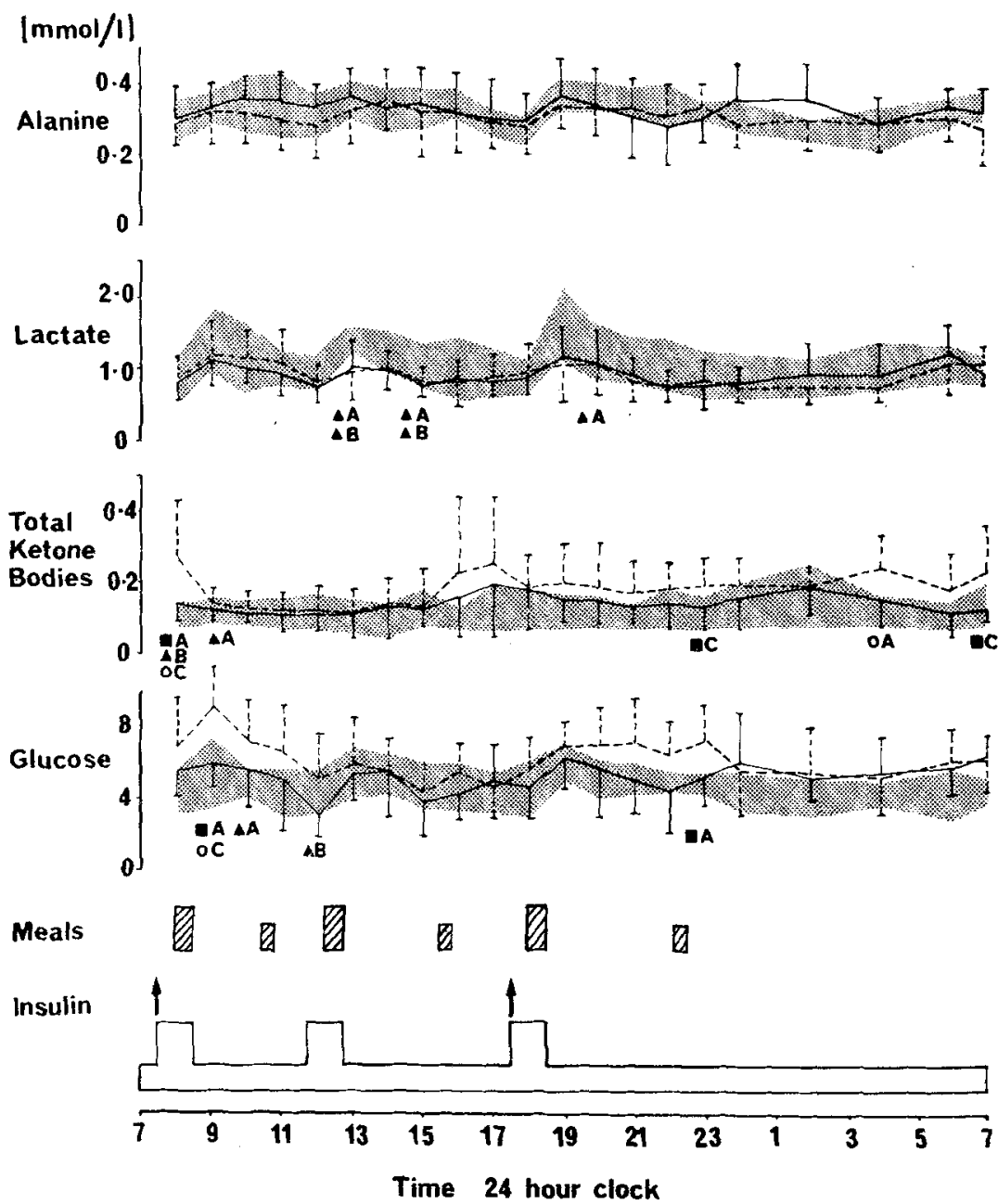

Fig. 1. Mean \pm SD blood glucose, total ketone bodies, lactate and alanine concentrations during $24 \mathrm{~h}$ metabolic profiles in seven insulin-requiring pregnant diabetics on conventional insulin regimes (_-_ $)$ and subsequently on CSII (- - Mean \pm SD metabolite values in seven non-diabetic pregnant women in the third trimester are shown as hatched areas. Meals: large boxes represent main meals; small boxes represent snacks. Insulin: arrows represent time of insulin injections on conventional regimes; unshaded area represents basal and augmented mealtime infusion protocol. Comparison of groups: A -control versus conventional regime. $B$ - control versus CSII. C - CSII versus conventional regime. $\Delta p<0.05 ; \boldsymbol{\square} p<0.02 ; 0 p<0.01$

tional insulin regimes compared with controls $(p<$ $0.05)$ and compared with the use of CSII $(p<0.01)$, there being no difference between levels in diabetics on CSII and controls. The variability in ketone body levels in the individual patients was much worse in the diabetics treated with conventional insulin regimes than the controls $(p<0.05)$ but this was significantly improved by CSII $(p<0.01)$. In diabetics treated with conventional insulin regimes, total ketone body levels were raised above the controls at many time points during the day and significantly so at $08.00,09.00$ and $04.00 \mathrm{~h}(p<0.02, p<0.05$ and $p<0.01$ respectively; Fig. 1). CSII was associated with significant reductions in total ketone body levels in the morning $(07.00$ and $08.00 \mathrm{~h})$ and evening $(23.00 \mathrm{~h})(p<0.02, p<0.01$ and $p<0.02$ respectively) so that levels were similar to those seen in the controls throughout the day with the exception of $08.00 \mathrm{~h}(p<0.05)$.

Mean $24 \mathrm{~h}$ lactate levels (Table 3 ) in the controls were no different to those in the diabetics before or during CSII. The blood lactate showed a pronounced increase after meals (Fig. 1). These post-prandial peaks were significantly smaller in the diabetics before CSII at 13.00 and $20.00 \mathrm{~h}(p<0.05$ at each time) and on CSII at $13.00 \mathrm{~h}(p<0.05)$ compared with controls. Levels in the diabetics before and after CSII were very similar. Mean alanine levels in the controls were similar to those in the diabetics before and after CSII (Table 3). In all cases there was a gradual rise and fall in blood alanine after meals but there were no significant differences between the groups.

\section{Discussion}

The use of open loop insulin infusion systems has been shown not only to achieve near normoglycaemia in diabetics but also to eliminate the peaks and troughs in blood glucose levels associated with the use of conventional insulin regimes $[20,21]$. This technique seems to be effective whether the IV or SC delivery route is used $[21,22]$ but CSII is more attractive 
in the long-term treatment of patients. It is now well established that CSII normalises not only blood glucose but also other metabolites involved in glucose metabolism [23, 24]. The ability of patients to tolerate CSII for long periods [25] makes it an attractive possibility for use in diabetic pregnancy where strict metabolic control is required for a limited period of time.

In this study of hospitalised diabetics in the third trimester of pregnancy, very good glycaemic control was achieved by the use of either optimised conventional insulin regimes or CSII, which is in keeping with the findings of Champion et al. [25] and Rizza et al. [26] in hospitalised non-pregnant diabetics. As far as mean $24 \mathrm{~h}$ glucose values are concerned CSII does not have any demonstrable advantage over the conventional insulin regimes we used but it may have a significant clinical advantage in reducing post-breakfast glucose peaks.

CSII produced a significant reduction in the mean as well as the variability of ketone body levels throughout the day, and it is likely that this is due to the more constant supply of insulin in the basal state. Whilst the effect of ketone body production in the developing foetus is still undetermined, there is evidence to suggest that increased ketone levels in the mother during pregnancy may impair the intellectual development of the offspring [27, 28]. It would seem appropriate therefore to use insulin regimes in diabetic pregnancy that will supply sufficient insulin throughout $24 \mathrm{~h}$ to control ketone body production.

Post-prandial rises in blood lactate levels are characteristically seen in normal people and probably occur as a result of increased glycolysis [29]. Although the diabetics had very similar lactate levels before and after CSII, post-prandial elavations were still evident but were not so pronounced as those seen in normal women. This might be due to insufficient insulin or to decreased dietary carbohydrate intake. Amino acid levels may be important in diabetic pregnancy because of their possible influence on foetal pancreatic development and insulin secretion [30]. There have been suggestions that at least some amino acids are high in the basal overnight state and may rise higher and remain elevated longer after meals in diabetics than in normal subjects [9]. The alanine levels in this study however, whilst not being representative of amino acid metabolism as a whole, were remarkably similar in the controls and diabetics before and during CSII.

The infusion system used in this study has been shown to be a practical and reliable technique. There were no episodes of battery or pump failure and no local complications at the infusion site. Furthermore, control of diabetes was sustained for long periods in individual patients without any major hypoglycaemic attacks and in selected patients could be continued whilst at home during the weekend. The acceptability of the technique to the patient could be improved by the further miniaturisation of the infusion pump and the development of fail-safe warning systems.

This study demonstrates that close attention to conventional insulin regimes in in-patient pregnant diabetics can result in metabolic control that is very close to that seen in normal pregnant women of the same gestational age, although ketone body levels still remain significantly elevated. The use of CSII in the same women significantly reduces ketone body levels and achieves mean $24 \mathrm{~h}$ metabolite levels similar to those in non-diabetic pregnant women.

This suggests that CSII is of potential benefit in the management of diabetics in situations such as pregnancy where the best possible control is required for a limited period of time.

Acknowledgements. We would like to thank Drs. R. V. Hague and J. D. Ward for allowing us to study patients under their care, and Professor I. D. Cooke, Mr. A. Johnson, Mr. W. Porter and Mr. $\mathrm{T}$. Smith for cooperation in the obstetric management of these patients. J. M. P. was supported by a Novo Research Fellowship.

\section{References}

1. Gellis SS, Hsia DYY (1959) The infant of the diabetic mother. Am J Dis Child 97: 1-41

2. Kyle GC (1963) Diabetes and pregnancy. Ann Intern Med 3 (Suppl): 1-82

3. Pedersen J, Brandstrup E (1956) Foetal mortality in pregnant diabetics. Lancet 1:607-610

4. Pedersen J, Molsted-Pedersen L, Andersen B (1974) Assessors of fetal perinatal mortality in diabetic pregnancy. Diabetes 23 : 302-309

5. Gabbe SG, Mestman JH, Freeman RK, Goebelsmann UT, Lowensohn RI, Nochimson D, Cetrulo C, Quilligan EJ (1977) Management and outcome of pregnancy in diabetes mellitus, classes B to R. Am J Obstet Gynecol 129: 723-728

6. Roversi GD, Gargiulo M, Nicolini U, Pedretti E, Marini A, Barbarani V, Peneff P (1979) A new approach to the treatment of diabetic pregnant women. Am J Obstet Gynecol 135: $567-576$

7. Pedersen J (1977) Hyperglycaemia - hyperinsulinism theory and birth weight. In: The pregnant diabetic and her newborn, 2nd edn. Munksgaard, Copenhagen, pp 211-217

8. Karlsson K, Kjellmer I (1972) The outcome of diabetic pregnancies in relation to the mother's blood sugar level. Am J Obstet Gynecol 112:213-220

9. Freinkel N, Metzger B (1979) Pregnancy as a tissue culture experience: the critical implications of maternal metabolism for fetal development. In: Elliott K, O'Connor M (eds) Pregnancy metabolism, diabetes and the fetus. Ciba Foundation Symposium 63 (new series) Excerpta Medica, Amsterdam Oxford New York, pp 3-23

10. Pickup JC, Keen H, Parsons JA, Alberti KGMM (1978) Continuous subcutaneous insulin infusion: an approach to achieving normoglycaemia. Br Med J 1:204-207 
11. Tamborlane WV, Sherwin RS, Genel M, Felig P (1979) Reduction to normal of plasma glucose in juvenile diabetes by subcutaneous administration of insulin with a portable infusion pump. N Engl J Med 300: 573-575

12. Pedersen J (1977) Fetal mortality. Classification of diabetic pregnancy. In: The pregnant diabetic and her newborn, 2nd edn. Munksgaard, Copenhagen, pp 198-210

13. Fitzgerald MG, Keen H (1964) Diagnostic classification in diabetes. Br Med J 1: 1568

14. Bergmeyer HU, Bernt E, Schmidt F, Stork H(1974) D Glucose. Determination with hexokinase and glucose-6-phosphate dehydrogenase. In: Bergmeyer HU (ed) Methods of enzymatic analysis. Academic Press, New York, pp 1196-1201

15. Gutmann I, Wahlefeld AW (1974) L (+)-lactate. Determination with lactate dehydrogenase and NAD. In: Bergmeyer HU (ed) Methods of enzymatic analysis. Academic Press, New York, pp 1464-1468

16. Williamson DH (1974) L-Alanine. Determination with alanine dehydrogenase. In: Bergmeyer HU (ed) Methods of enzymatic analysis. Academic Press, New York, pp 1679-1682

17. Williamson DH, Mellanby J (1974) D-(-)-3-hydroxybutyrate. In: Bergmeyer HU (ed) Methods of enzymatic analysis. Academic Press, New York, pp 1836-1839

18. Price CP, Lloyd B, Alberti KGMM (1977) A kinetic spectrophotometric assay for the rapid determination of acetoacetate in blood. Clin Chem 23:1893-1897

19. Armitage P (1971) Statistical methods in medical research. Blackwell Scientific Publications, Oxford London Edinburgh Melbourne, $p 123$

20. Slama G, Hautecouverture M, Assam R, Tchobroutsky G (1974) One to five days of continuous intravenous insulin infusion on seven diabetic patients. Diabetes 23: 732-738

21. Deckert T, Lorup B (1976) Regulation of brittle diabetics by a pre-planned insulin infusion programme. Diabetologia 12: 573-579

22. Pickup JC, Keen H, White MC, Parson JA, Alberti KGMM (1979) Long-term continuous subcutaneous insulin infusion in diabetics at home. Lancet 2:870-873

23. Pickup JC, Keen H, Parsons JA, Alberti KGMM, Rowe AS (1979) Continuous subcutaneous insulin infusion: improved blood glucose and intermediary metabolite control in diabetics. Lancet 1 : 1255-1257
24. Tamborlane WV, Sherwin RS, Genel M, Felig P (1979) Restoration of normal lipid and amino acid metabolism in diabetic patients treated with a portable insulin infusion pump. Lancet 1:1258-1261

25. Champion MC, Shepherd GAA, Rodger NW, Dupre J (1980) Continuous subcutaneous infusion of insulin in the management of diabetes mellitus. Diabetes 29:206-212

26. Rizza RA, Gerich JE, Morley HW, Westland RE, Hall LD, Clemens AH, Service FJ (1980) Control of blood sugar in insulin-dependent diabetes: comparison of an artificial endocrine pancreas, continuous subcutaneous insulin infusion, and intensified conventional insulin therpay. N Engl J Med 303: 1313-1318

27. Churchill JA, Berendes HW, Nemore J (1969) Neuropsychological deficits in children of diabetic mothers. Am J Obstet Gynecol 105: 257-268

28. Stebhens JA, Baker GL, Kitchell M(1977) Outcome at ages 1, 2 and 5 years of children born to diabetic women. Am J Obstet Gynecol 127:408-413

29. Alberti KGMM, Dornhorst A, Rowe AS (1975) Metabolic rhythms in normal and diabetic man. Israel J Med Sci 11: $571-580$

30. Milner RDG, de Gasparo M, Milner GR, Wirdnam PK (1979) Amino acids and development of the beta cell. In: Sutherland HW, Stowers JM (eds) Carbohydrate metabolism in pregnancy and the newborn. Springer, Berlin Heidelberg New York, pp 132-151

31. Weights of insured persons in the United States associated with lowest mortality (1959) Statistical Bulletin of the Metropolitan Life Insurance Company, $\mathrm{p} 40$

Received: 22 April 1980

and in revised form: 10 July 1981

Dr. D. R. Cullen

Royal Hallamshire Hospital

Glossop Road

Sheffield

S10 2JF, UK 